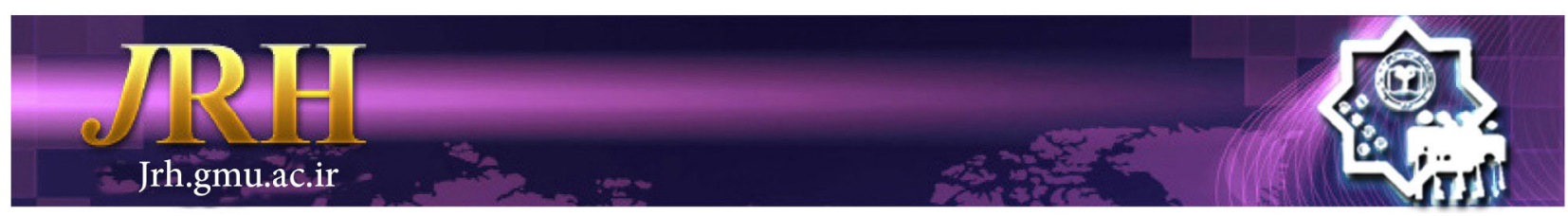

\title{
The wisely services of libraries as the predisposing factors of social health: a grounded theory approach \\ Alireza Atarodi Beimorghi ${ }^{1}$, Nadjla Hariri ${ }^{1}$, Fahimeh Babalhavaeji ${ }^{1}$
}

\author{
Journal of Research \& Health \\ Social Development \& Health Promotion \\ Research Center \\ Vol. 8, No. 2, Mar \& Apr 2018 \\ Pages: $132-142$ \\ DOI: $10.29252 /$ jrh.8.2.132 \\ Original Article
}

1. Department of Knowledge and Information Science, Science and Research Branch, Islamic Azad University, Tehran, Iran

Correspondence to: Nadjla Hariri, Department of Knowledge and Information Science, Science and Research Branch, Islamic Azad University, Tehran, Iran

Email: nadjlahariri@gmail.com

Received: 19 Feb 2017

Accepted: 9 Nov 2017

How to cite this article: Atarodi Beimorghi A, Hariri N, Babalhavaeji F. The wisely services of libraries as the predisposing factors of social health: a grounded theory approach. $J$ Research \& Health2018; 8(2): 132- 142.

\begin{abstract}
Knowledge is the real and necessary requirement of today's societies, and we benefit from information and knowledge in our lives and promote our health through it. Health is a category that is important in life and several factors can affect its formation, sustainability and promotion. Libraries, and librarians as facilitators of knowledge dissemination, can promote social health through managing and transforming knowledge into wisdom, providing intellectuality, and internalizing knowledge in human and throughout the community. The purpose of this study was to explain the rational use of libraries as the main causes of social health by using a qualitative method and resorting to grounded theory approach. Participants in this study were 22 educated people at least with $\mathrm{PhD}$ degree, which were considered to be rich in information on the research subject. The participants were selected by purposeful sampling method. The data were collected using semi-structured interviews while the interviews were ended in saturation phase or in the theoretical adequacy. Data analysis was performed using the Strauss and Corbin method or three stages of open, axial, and selective coding. After analyzing data, 300 initial open codes, about 100 merged codes, 20 sub-sub categories, 9 sub-categories, and 3 main categories were appeared. The main category was "The wisely services of libraries as the predisposing factors of social health." The findings showed that libraries can play an effective role in the formation and promotion of social health using their resources and librarians' capabilities.
\end{abstract}

Keywords: Intellectuality, Knowledge, Library, Social Health, Wisdom

\section{Introduction}

We as human needs health since health guarantee the survival of the human race. A healthy thinking requires special conditions and is obtained through proper training. Education plays an essential role in health promotion. Proper education is formed by studying and acquiring wisdom and rooted in studying, surveying valuable experiences, and applying the acquired knowledge in the context of the society [1].

Libraries have always been a place for accessing information and have been tied up with education and research. Providing educational resources is part of the activity of 
libraries in the field oflearning. Learning services include all potential and actual audience at the community level, and in particular, specific groups. In fact, it can be said that a library has an active and effective role in spreading knowledge in the society [2]. Therefore, the experience and available resources to educate and promote health to others can be provided by books, libraries resources, and knowledge disseminators. Information resources can play an essential and influential role in the promotion of individual and community health. Libraries help community members to create a better life in the world. Public libraries play a major role in fostering a nation, researchers and scientists. Libraries create and expand the horizons of the society and improve the wisdom and intellectuality, the role of community and self-learning, and creativity and leisure time. Public libraries are also a place for accessing information, a platform for learning and learning through the creation and strengthening of the habits of studying in individuals and the availability of easy access to various resources [3]. The creation and promotion of social health requires the ability to study, understand, and apply health information and knowledge as well as the ability to strengthen wisdom and effective behaviors in the society [4].

Knowledge by itself cannot change people's lives unless it is transformed into wisdom and make human wiser. Knowledge is what people believe in it and formed through meaningful organization of meaningful information by experience, communication or inference. However, wisdom is defined as a system for accumulation of practical and applied knowledge, insight, judgment, and awareness in unclear complex issues and it is as a kind of skill for guiding a meaningful life [5].

Human social health grows by wisdom and intellectuality. In order to prevent and vaccinate today's human life against the massive flood of dilemmas and challenges, to create and build a healthy social life or comprehensive social health, the society needs effective antibodies and antidotes, such as knowledge and wisdom. We should do some changes and this change always needs some conditions in the society. These changes include changing people's thoughts to promote morality, beliefs, and attitudes of the human being, and the possibility of making a healthy society [6].

Although social health has different definitions in different cultures, there is no definitive theory about it, and it is difficult to provide a precise definition for it [7], some researchers, such as Keyes [8] considered five dimensions for social health.

In general, the dimensions of social health that can be achieved through knowledge and wisdom and can lead to a healthy social life and social health are as follows based on the ability of libraries in the society: social cohesion, social acceptance, social adaptation, social participation, and social self-actualization $[9,10]$.

Accordingly, it seems that social health for human being and the survival of his life is important and any kind of progress and promotion can be slowed down or difficult and lead life into a wrong way without any healthy and social life as well as a safe and prosperous society. Therefore, human needs to rely on his potential ability and intellectuality to gain knowledge and experience from others. Moreover, he needs to institutionalize or internalize the results of knowledge in personal and social behaviors, so in this way we may be able to rid human of the challenges and the problems he is faced with them today [11,12].

On the other hand, due to the high cost of creating and expanding libraries and information centers and providing the needed resources, Libraries can play a fundamental role in facilitating and accelerating the formation of social health. Recognizing and using these knowledge centers for the community can make it easier and more convenient to make it more accessible to a healthy society at a lower cost. Therefore, considering the importance and necessity of a healthy life and social health, which should be based on accurate and deeper information, seems more necessary. Then with impact 
of social contexts, and the reception of the human mind rational constituents, we aimed to survey "the wisely services of libraries as the predisposing factors of social health", in a qualitative research method, to reach a theory to have a deep link with our data.

\section{Method}

This qualitative research was conducted using the grounded theory method. The grounded theory was used to gain the views, and the perceptions of the participation in the field of thought, the processes forming social interactions and development of theory on the subject. Twenty two knowledgeable participants from different fields of science in Tehran, Mashhad, Isfahan, northern Iran, Birjand, and Gonabad were selected through purposeful sampling. According to Khorasani 2008, people who are rich of information in the field are people who are relatively aware of their community and are willing to share their information with others [13].

The least criterion for choosing samples was having a $\mathrm{PhD}$ degree, an assistant professorship, and job experience of more than 5 years, and publishing at least 1 title and 5 original research papers. Deep structured interviews were performed for collecting information. The location of interview was determined by the participants. All ethical issues were observed during the interview. Each interview lasted from 40 to 50 minutes.

The interviews were recorded with a small tape recorder. During the interview, the participants were asked general questions. The questions were about the services of libraries and librarians, their sources and the ability of the information centers, knowledge as the determinants of social health through collecting, processing, producing, distributing and publishing appropriate information in the right time for suitable people and how to acquire knowledge, institutionalizing and internalizing knowledge and its results on people and social behaviors, the way of transforming knowledge into wisdom, and their impact on making social health components.

The main question in this study was "what is the wisely services of libraries as the predisposing factors of social health from the point of view of the experts?" To be deeper in questions, some exploratory terms such as: how, why, who, when and where were asked, too.

Interviews and data gathering continued to reach data saturation stage, and the theoretical saturation criterion was when no new data was obtained, and newer and additional content was not collected or re-emerged, and no new insights was obtained.

To analyze the data, Strauss and Corbin in 1998 method was used in three stages of open coding (reviewing, comparing, conceptualizing and categorizing data), axial coding (data retrieval in groups based on the relationships and patterns within and between identified categories in the data), and selective coding (identifying and describing the central phenomenon or "categories" in the data) was used [14].

The credibility of the data was measured using the proposed indicators quoted by Guba and Lincoln in 1994, or with 4 criteria such as 1 ) Credibility or acceptability (continuous presence in the research environment, sending some of the texts implemented to participate for correcting and verification of the text (reflex mode) for individual control) 2) Reliability and dependability (accurate recording and maintenance of all details about how data was collected and decisions making method, interpretations and analyzes carried out in research process). 3) Conformability, the quality of conforming (through systematic recording of all documentation related to research data as well as inferences, interpretations and findings, accurate report of the process, the research and path of decisions during the research, and 4) The transferability and observance of accuracy in recording by preserving, analyzing data and agreeing with two coders outside the research area for validation and reliability of the data were also evaluated and confirmed [15].

Therefore, attempts were made to select participants with different experiences and opinions and to avoid personal opinion 
leading to bias. The participants at all stages of the research considered the necessary ethical considerations related to research and in relation to the participants and tried to fulfill moral obligations. We used descriptive statistics for analyzing demographic information, and three stages coding for main data of the research and MAXQDA-10 software were also used.

\section{Results}

The participants were 17 men and 5 women and their academic degree was $\mathrm{PhD} 12$ (54.55\%) of the participants were in knowledge and information sciences field, $2(9.09 \%)$ in Persian literature, 3 (12.62\%) in social sciences field, $4(18.18 \%)$ in Islamic philosophy and wisdom, and $1(4.54 \%)$ also was in history field that participated in our study. Moreover, $16(72.73 \%)$ participants were working and 6 $(27.27 \%)$ were retired during the interviews.

Table 1 shows an example of the results of open coding, concepts, subcategories, and subclasses and the main classes for the opinion of the experts.

Table 1 An example of open coding, explaining wisely services of libraries, information centers, librarians, and social media-based informants from experts' point of view

\begin{tabular}{|c|c|c|c|}
\hline $\begin{array}{l}\text { Sub categories } \\
\text { (sub sub-classes) }\end{array}$ & $\begin{array}{l}\text { Main Categories } \\
\text { (sub classes) }\end{array}$ & Main Classes & $\begin{array}{l}\text { Final Class } \\
\text { (phenomenon) }\end{array}$ \\
\hline $\begin{array}{l}\text { The base of studying the works, sources and } \\
\text { experiences of scholars and wise men }\end{array}$ & \multirow{3}{*}{$\begin{array}{l}\text { Library as the base of } \\
\text { accessing, studying and } \\
\text { producing knowledge, wisdom } \\
\text { and intellectuality }\end{array}$} & \multirow{8}{*}{$\begin{array}{l}\text { Libraries as the base } \\
\text { of making wisdom, } \\
\text { intellectuality and a factor } \\
\text { for promotion of social } \\
\text { health }\end{array}$} & \multirow{20}{*}{ 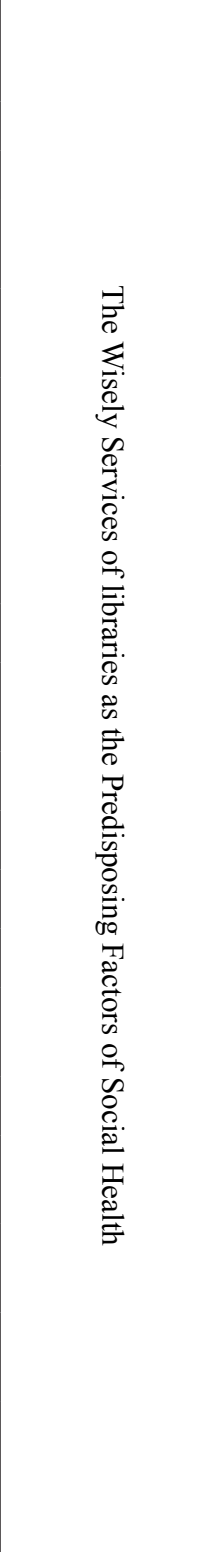 } \\
\hline Deep and effective use of library sources & & & \\
\hline library as the bedrock of wise making & & & \\
\hline $\begin{array}{l}\text { Libraries as the center of collecting } \\
\text { information and useful knowledge }\end{array}$ & \multirow{3}{*}{$\begin{array}{l}\text { Libraries as the base of } \\
\text { disseminating proper and } \\
\text { useful information }\end{array}$} & & \\
\hline $\begin{array}{l}\text { Creating and disseminating right } \\
\text { information in the right time }\end{array}$ & & & \\
\hline $\begin{array}{l}\text { Libraries as the bedrock of disseminating } \\
\text { useful knowledge }\end{array}$ & & & \\
\hline Librarians as the managers of knowledge & \multirow{2}{*}{$\begin{array}{l}\text { Librarian as the facilitator } \\
\text { of making knowledge and } \\
\text { wisdom }\end{array}$} & & \\
\hline $\begin{array}{l}\text { Librarians as facilitators of making wisely } \\
\text { knowledge }\end{array}$ & & & \\
\hline The factor of usefulness and health of living & \multirow{3}{*}{$\begin{array}{l}\text { Library as the bedrock of } \\
\text { social health and prosperity }\end{array}$} & \multirow{6}{*}{$\begin{array}{l}\text { Library as the base and } \\
\text { maker of social health and } \\
\text { prosperity }\end{array}$} & \\
\hline $\begin{array}{l}\text { Library as the base of prosperity and } \\
\text { relaxation of the society }\end{array}$ & & & \\
\hline Library as the factor of social health & & & \\
\hline Life proper strategy & \multirow{3}{*}{$\begin{array}{l}\text { Library the former of a true } \\
\text { and prosperous life }\end{array}$} & & \\
\hline The cause of prosperity & & & \\
\hline The factor of welfare and a healthy living & & & \\
\hline The way of social participation & $\begin{array}{l}\text { The factor of social } \\
\text { participation }\end{array}$ & \multirow{6}{*}{$\begin{array}{l}\text { Social health based on } \\
\text { book, reading books and } \\
\text { knowledge internalizing }\end{array}$} & \\
\hline The factor of social security & \multirow{2}{*}{$\begin{array}{l}\text { Book and book reading as the } \\
\text { factor of social security }\end{array}$} & & \\
\hline $\begin{array}{l}\text { The factor of health and formidability of } \\
\text { living }\end{array}$ & & & \\
\hline $\begin{array}{l}\text { The impact of book and reading books on a } \\
\text { healthy living }\end{array}$ & \multirow{2}{*}{$\begin{array}{c}\text { The effect of book and reading } \\
\text { books on establishment and } \\
\text { development of a healthy } \\
\text { living }\end{array}$} & & \\
\hline $\begin{array}{l}\text { Books and book reading as the base of } \\
\text { social florescence and development }\end{array}$ & & & \\
\hline $\begin{array}{l}\text { Applying and operationalizing useful } \\
\text { results of knowledge for establishing and } \\
\text { growth of an ideal society based on books, } \\
\text { reading books, library and librarians ability }\end{array}$ & Applying useful knowledge & & \\
\hline
\end{tabular}


After reviewing and analyzing the data obtained from the interviews, 300 initial codes was obtained using open coding and then merged into 100 codes. There were 20 subcategories or sub-subclasses that were merged into 9 categories or subclasses and ultimately divided into 3 main categories and 1 class or final phenomenon, which was in accordance with the development of the research theory, titled "the wisely services of libraries as the predisposing factors of social health" that was appeared and formed from the data, and then results were included in the table above.

In addition to the above issues and according to the commentary of the participants, it is important to consider the role of libraries in the preparation, compilation, collection, organization, processing, production, and dissemination of information to make the necessary information ready for the public, researchers and community members, and to create a platform for discussing, interacting and exchanging uncensored thoughts, creating a pleasant atmosphere for education. We should also value the role of libraries in maintaining peace, building peace and friendship, building and fostering creativity in children, and encouraging each individual to be a better and more fruitful member in the society. Libraries have the power for establishing a spirit of cooperation and participation, creating a spirit of tolerance, patience, and resistance, reproducing positive qualities in people through studying and book reading in order to solve community problems. Libraries act as a bridge between people from the elite to the public, and so on that the participants referred to the above items in their interviews. It can be said that the foundation of powerful libraries for creating a safe and secure community based on the rational use of libraries and knowledge perpetrators should be formed to provide us a path to an ideal society and fit a good living for human and social development. The main classes and examples of participants' sentences on the topic of the research are presented under 3 main categories and subcategories based on the research data.
1) Libraries as the base of social health development through wisdom and intellectuality:

As the participants reported, libraries and information centers are considered as a place for studying the books, resources, and experiences of scholars and intellectuals; in addition, they believed that the experience and perspectives on wisdom are recorded and preserved in the written texts. The information resources are maintained at these centers, called libraries and information centers, in order to be accessible for the public and mostly focus on wisdom and intellectuality by processing and operating the results of knowledge. Subcategories of the first, the second, and the third main categories of the research and some samples of the participants' comments and sentences (along with their identification code, age, and their academic degree) are presented as the followings.

1.1) Libraries as the base of accessing, studying, and producing knowledge, wisdom, and intellectuality: Libraries are the place and the center for studying books and works of the scholars and intellectuals of the society and also the circle of scientific debates. Libraries are also the necessary platform for accessing, studying, and producing wise knowledge to create and crystallize the culture of wisdom and intellectuality. They can institutionalize and bring about the results of knowledge for community members in the society, too.

- "Studying the biography of the wise men, the books written on wisdom are also effective." (Participant No. 1, age: 71, PhD).

"There are several good books in the field of knowledge management in libraries to be studied." (Participant No. 16, age: 49, PhD). "It is not possible to acquire knowledge and to make it practical and transforming knowledge into wisdom without studying" (Participant No. 11, age: $48, \mathrm{PhD})$.

"Libraries in schools can also play an effective role in institutionalizing of information and knowledge" (Participant No. 15, age: 40, $\mathrm{PhD}$ ).

1.2) Libraries as the platform for publishing 
useful information: The main mission of the libraries is to collect the information and knowledge by librarians and information scientists to produce and disseminate knowledge by the help of experts and scientists. This can be done in order to provide useful knowledge for educating humans and society and to improve culture and to form civilization and provide the necessary and useful information for the enthusiasts and researchers. Librarians and knowledge managers can fulfill knowledge and scientific gap and provide the necessary platform for the establishment of a healthy and prosperous society based on knowledge and wisdom.

"The exact philosophy of the libraries is to provide the information, knowledge, and skills people need." (Participant No. 20, age: 63, $\mathrm{PhD})$.

"The impact of libraries, authors, and librarians on knowledge dissemination, development, and prosperity of culture and science is important" (Participant No. 11, age: 48, PhD).

"Librarians are involved because they can act as mediators and provide tools that can be used to fundamentally produce the knowledge needed for transforming into wisdom or for transferring of knowledge" (Participant No. 18 , age: $35, \mathrm{PhD}$ ).

"In addition the library, apart from its traditional services, can create a forum where all the intellectuals, scholars and experts be able to express themselves there, speak, and then make a knowledge gathering in the library" (Participant No. 3, age: 65, $\mathrm{PhD}$ ).

1.3) The librarian as the agent of knowledge and wisdom creation: Knowledge on its own is not transformed into wisdom and intellectuality, and requires experts and managers who have the necessary expertise in the management of information and knowledge production. Information and knowledge managers so called the librarians make and produce knowledge from collecting, compilation, classification, processing, production, dissemination, publication, evaluation and using feedback of information and knowledge application and they are also expert in knowledge transferring and are a bridge between knowledge producers and consumers, too.

"Librarians are involved because they can act as mediators and provide tools that can be used to produce or fundamentally transform this knowledge into wisdom, and today the role of the librarian is actually much wider" (Participant No. 18, age: 35, $\mathrm{PhD}$ ).

- "Books like Golestan, Bostan, Shahnameh, and Nahjolbalaghe are books that are examples of wisdom, but most of them are theories and have not been practical and operational" (Participant No. 9, age: 70, PhD).

"A free thinking society that seeks to transform knowledge into wisdom requires a librarian, book and book publishing, and rich libraries with free access and no limitation." (Participant No. 11, age: 48, PhD).

"Knowledge processing can become widespread. Librarians and libraries can very well help to create a space to provide easy access to knowledge resources, and make many people connected to the library, especially scholars and knowledge producers to create a scientific and cultural environment.“ (Participant No.3, age: 65, $\mathrm{PhD}$ ).

2) The library as the agent of culture, the foundation and a place for health promotion and prosperity of the society:

The book and the library need reader; in other words, library resources are prepared and organized for reading. A library can encourage readers to study and read books and encourage the growth and development of community members. Improving the study culture and habit of studying is of duties and functions of libraries and information centers to the necessary conditions for making social well-being over the time with patience through studying and the effect of studying and reading books on human community members to improve the health status and the prosperity of the community.

Therefore, as the participants said, library was as an agent for creating and improving culture through studying, reading books and as the bedrock of the community's health and prosperity. Subcategories of the second main 
category of the research, along with a sample of the participants comments, resulted from the interviews are as follows.

2.1) The library as the agent and the base of health and social happiness: The human community needs its own health and survival, and then a society can be prosperous and meet happiness when it is healthy. A comprehensive and sustainable health guarantee can be derived from knowledge and to use and apply the results of that knowledge. A society will meet health and well-being to appreciate and value knowledge and try to put its results into practice in the society.

"All the people cannot be wise, but if they benefit from this result, it will be useful for their lives." (Participant No. 14, age: 34, PhD). "I think the specialized libraries can be more effective in this area." (Participant No. 15, age: 40, $\mathrm{PhD})$.

"Libraries are important in using leisure time well, learning how to respect each other, enhancing children creativity, and informing how to make peace in the society." (Participant No. 11 , age: $48, \mathrm{PhD}$ ).

2.2) Libraries as the maker of truth and a happy life: Guiding a society towards a purposeful and right social life for the sake of prosperity is passed through a transparent, appropriate, and useful way of awareness. A wisely shaped society is based on knowledge and its results must be injected from knowledge centers to the society to show the right path and prosperity to human beings for a better living and a safe and prosperous society that this agent is in the power of libraries and knowledge treasures.

"It is a kind of practical wisdom that shows people how to live happily." (Participant No. 18, age: $34, \mathrm{PhD}$ ).

"Yes, they can work. Of course, the book and the library need reader even if today there are books and libraries, but there are a few readers and may no reader, however, books and book reading have positive impact and there are different ways to study books." (Participant No. 2, age: $76, \mathrm{PhD}$ ).

"Libraries, books, digital libraries, the society itself, and the community itself, are the entire hardware sector; you need also to have those resources available for readers." (Participant No. 8, age: 56, $\mathrm{PhD}$ ).

3) Social well-being and relaxation based on reading books and internalizing knowledge: One of the tasks of libraries, and especially public libraries, is to fill people's leisure time so that they be able to study and shape themselves as a better member of the human community and may thus play a better role in the society. Then, the participants claimed to another function of the library as the actors of knowledge and the formation of wisdom. The subcategories of the third main category of the research, along with a sample of its documentation are as follow.

3.1) Book as the agent of social participation: Book reading has a lot of positive outcomes for human. Those people who are studying books, show different and proper human characteristics, they have a better social behavior, and they also show more positive contributions. The level of social participation in a literate society is high and has a high rank. In other words, the level of literacy is in consistent with participation level in social affairs.

"Why the French people read many books when they are in the bus, in train or in the bakery, but we do not, because they are more literate and informed. They have a society based on science. They encourage them to read books, scientific discussion, and to contribute to their own destiny, then, they find their way" (Participant No. 4, age 53, PhD). "When knowledge or science is transformed into wisdom, science and art, wisdom and all of them are emerged and appeared as the common property and behavior of the society". (Participant No. 6, age: 51, PhD).

- "The social partnership in a book readers and wise society is high." (Participant No. 11, age: $48, \mathrm{PhD})$.

"Science, in their view, has a collective identity, that is, with the participation of all, we can produce and reproduce this science." (Participant No. 5, age: 50, PhD).

3.2) Reading book as social security agent: 
Security is an important factor in the consistency of societies; a society that has no security has no living. The factors establishing security are internal and external. The internal factors can be health status, well-being, and the extent of the culture of human beings in the society, and these items make the security of a community. Libraries, reading books, and studying in general play an important role in providing security in the society. The external factors also can be such as regional and international threats and diplomatic problems.

"If the human beings act based on wisdom, it will be better for their own physical and mental health, I think specialized libraries can also be effective in this area." (Participant No. 15, age: 40, PhD).

- "He can manage his life; especially in crisis, a man who is wise never lose his way in the crisis." (Participant No. 18, age: 34, PhD).

3.3) The effectiveness of books and reading books on the creation and promotion of a healthy society: Reading and studying books has a significant impact on society. An unconscious and illiterate society is alien to its culture, which in turn undermines the growth and promotion of a vibrant, dynamic, and healthy society. Building and creating a rich, growing, and prosperous society can be based on the use of the experiences and knowledge of the past and the wise men of the past and will form the necessary effects for the society to meet health and prosperity.

- I do not feel it is ineffective. It is very influential. For example, one of the factors that can create health in a country is the Press; the release of the Press itself will make and encourage the habit of reading books. (Participant No. age: 13, 68, PhD).

"The library is important in fulfilling the leisure time, growth, mind creativity, and the social spirit" (Participant No. 11, age: 48, PhD).

- "You should refer to ethical books because they discuss the kinds of virtues and types of vices, ethical affairs, and scholars debate on them". (Participant No. 12, age: 60, PhD).

- "It is transforming of knowledge into wisdom that is important, because it is connected with the health of the people in the society, and is vital for individuals health." (Participant No. 18 , age: $35, \mathrm{PhD})$.

\section{Discussion}

Considering the main question of the research and extraction of the concepts and categories resulted from the collected data based on the question that "how is the wisely services of libraries as the main factor of making social health from their views?" it was cleared that libraries and information centers as knowledge management, storage, and transferring centers of knowledge have a significant role in sharing the right knowledge for the right people at the right time and in a right way.

Yesterday's librarians and today's knowledge professionals transform data into information through cataloging, organizing and creating Meta data, and provide the status of wisdom and knowledge in the community. These results are consistent with the results of Malekifar [16] Zare Gawkani et al., [2], Niknam et al., [3], Abbasi Hormozi [17], and Soltani et al., [18].

The results of the research mentioned above indicate that libraries can help people to create a better life in the world. Libraries have always been a place for accessing to information, and are united with education and research. The provision of educational resources is part of the activity of libraries in the field of learning. Therefore, it can be concluded that in fact the library, with the ability of yesterday and today of itself, both in terms of facilities, information and knowledge resources, experience, information processing, and the ability to publish information and informational system can have an active and effective role in developing knowledge and institutionalizing the results of knowledge in the society, which is the basis of social health. These statements are in consistent with the first category of the present study; namely, libraries as the bedrock and the producer of wisdom and rationale for social health.

The participants also claimed that books and libraries are as a platform for healthy living, 
life strategy and leadership, the factor of social prosperity, and consistency and sustainability of life. Knowledge is needed for right decisionmaking at the right time, a necessity for social participation and engagement, and libraries are center for collecting of resources and such affairs, and a way to understand or to realize these factors for making a happy and healthy life, which is in consistent with the results of Mashayekhi, [19], Kord-e-Noughabi [20] and Brugman [21].

Since the results of previous studies showed, it is possible to get to wisdom by studying the works and experiences of the wise ancestors stored in the libraries and information centers in general that affects life,. Then, proper management and mental health of the individuals and the human community, right direction of the life of individuals and the human society can result in happiness, consistency, interaction and social participation of the individuals, and will also increase in proportion to the increase of knowledge and wisdom and can guarantee the healthy survival of human life and social health.

According to Ferdowsi, stated by Mashayekhi [19], the only thing that enables a good person to know well from bad and, consequently, brings happiness to life, is the power of wisdom. In the opinion of Mashayekhi, nothing is superior than or equal to wisdom. The people with this gift can reach the level of insight and mind; and enjoy the both worlds. Those who benefit from wisdom tend to have more pleasure and live longer, and those who are not wise enough are suffering from sadness and, consequently, loss of life. These results are in consistent with the second and third categories of the present study titled "Library as the cause of improving culture, the context for the health and wellbeing of the society, place of studying and internalizing knowledge" to provide social welfare, too. Therefore, it seems that libraries generally have a positive impact on life and health of mankind, and if life is not based on book and books reading, knowledge, wisdom and intellectuality, it will not last for a longer time and it may be submerged every second.
Libraries are a platform for scientific development and knowledge provision, and librarians as agents and managers of knowledge facilitate the basis for transforming knowledge into wisdom and have the ability to create and develop a society close to the human ideal or the eastern ideal, the ideal society or making the Utopia of the West based on knowledge application, wisdom, institutionalization and internalization of the beneficial results of knowledge and researches. We should also further pave the way, eliminate, and reduce the barriers and challenges to facilitate and accelerate wisdom formation to institutionalize, and sustain social health in the human community. The individual and social health of human can be achieved through books, library, knowledge and wisdom. It can be made by forming the culture of studying, book reading, and promoting the culture of wisdom to provide health and well-being for the society.

\section{Conclusion}

Libraries, knowledge, and wisdom are important on health and especially social health providing a healthy, calm, prosperous society, and a safe living environment for humankind. The agents that can promote social well-being and welfare with a low cost are the ability and potential capacity of the libraries, information centers, knowledge, and wisdom of managers that should be regarded well and deeply.

A society without knowledge and transforming knowledge into wisdom in the society will not be successful, when it is not institutionalized and appeared in the thoughts, speeches, and behaviors of the community through book reading, library usage or studying, then, will not be able to make a dynamic, model, and healthy society. Therefore, it is desirable and necessary to focus some activities of libraries and knowledge centers on the promotion of social health.

Regarding the mission of libraries to increase the level of knowledge of the community, and also with regard to the capabilities of librarians 
and their existing resources, it is necessary to provide a suitable condition for supplying and providing information needs, creating book reading culture, the production and application of knowledge and the institutionalization and internalization of the beneficial results of knowledge and transformation of knowledge into wisdom and wisely behaviors in the community through libraries.

\section{Acknowledgments}

We greatly appreciate deputy research director of Tehran Islamic Azad University, and all the participants who kindly cooperated in conducting the current study.

\section{Contribution}

Study design: NH, FB, ARAB

Data collection and analysis: ARAB

Manuscript preparation: ARAB

\section{Conflict of Interest}

"The authors declare that they have no competing interests."

\section{Funding}

The author (s) received financial support for the research from the research deputy of Islamic Azad University, Science and Research Branch of Tehran.

\section{References}

1- Olfson M, Druss BG, Marcus SC. Trends in mental health care among children and adolescents. $N$ Engl $J$ Med2015; 373(11): 1079.

2- Alicke MD, Sedikides C. Self-enhancement and selfprotection: What they are and what they do. Eur Rev Soc Psychol2009; 20(1): 1-48.

3- Baumeister RF. Rethinking self-esteem: why nonprofits should stop pushing self-esteem and start endorsing selfcontrol. Stanford Soc Innov Rev2005; 3(4): 34-41.

4- Baumeister RF, Heatherton TF, Tice DM. When ego threats lead to self-regulation failure: negative consequences of high self-esteem. JPers Soc Psychol1993; 64(1):141- 56.

5- Meyers,SA. Personality correlation of adult attachment style. J Soc Psychol1998;138: 407-9.

6- Faria E, Blanes L, Hochman B, Mesquita Filho M, Ferreira L. Health-related quality of life, self-esteem and functional status of patients with leg ulcers. Wounds2011;
23(1):4-10.

7- Cunha M, Paiva MJ. Text anxiety in adolescents: the role of self-criticism and acceptance and mindfulness skills. Span J Psychol2012; 15(2): 533-43.

8- Shirk S, Burwell R, Harter S. Strategies to modify low self-esteem in adolescents. In: Reinecke MA, Dattilio FM, Freeman A, eds. Cognitive therapy with children and adolescents: A casebook for clinical practice. New York: Guilford press; 2003. pp: 189-213

9- American Psychiatric Association. Diagnostic and statistical manual of mental disorders (DSM-5®). American Psychiatric Pub; 2013 May 22.

10- Dalrymple KL, Galione J, Hrabosky J, et al. Diagnosing social anxiety disorder in the presence of obesity: implications for a proposed change in DSM-5. Depress Anxiety2011; 28(5): 377-82.

11- Brozovich FA, Goldin P, Lee I, Jazaieri H, Heimberg $\mathrm{RG}$, Gross JJ. The effect of rumination and reappraisal on social anxiety symptoms during cognitive-behavioral therapy for social anxiety disorder. J Clin Psychol2015; 71(3): 208-18.

12- Bratton SC, Ray D, Rhine T, Jones L. The efficacy of play therapy with children: a meta-analytic review of Treatment Outcomes. Prof Psychol Res Pr2005; 36(4): 376- 390 .

13- Piaget J. The relation of affectivity to intelligence in the mental development of the child. Bull Menninger Clin 1962; 26(3):129-37.

14- Drewes AA. Blending play therapy with cognitive behavioral therapy: Evidence-based and other effective treatments and techniques. John Wiley \& Sons; 2009.

15- Kazdin AE. Psychotherapy for children and adolescents: Directions for research and practice. London: Oxford university press; 2000.

16- Delle Carmichael K. Play therapy: An introduction. New Jersey, US: Pearson/Merrill Prentice Hall; 2006.

17- Landreth GL. Play therapy: The art of the relationship. New York: Routledge; 2012.

18- Kottman T. Adlerian play therapy. Int J Play Ther2001; 10(2): 1-12.

19- Ray D, Bratton S, Rhine T, Jones L. The effectiveness of play therapy: Responding to the critics. Int $J$ Play Ther2001; 10(1): 85-108.

20- Stangier U, Heidenreich T, Peitz M, Lauterbach W, Clark DM. Cognitive therapy for social phobia: individual versus group treatment. Behav Res Ther2003; 41(9): 991-1007.

21- Baggerly J, Parker M. Child-centered group play therapy with African American boys at the elementary school level. J Couns Dev2005; 83(4): 387.

22- Williams AD, O'Moore K, Mason E, Andrews G. The effectiveness of internet cognitive behaviour therapy (iCBT) for social anxiety disorder across two routine practice pathways. Internet Interv2014; 1(4): 
225-9.

23- Fracalanza K, McCabe RE, Taylor VH, Antony MM. The effect of comorbid major depressive disorder or bipolar disorder on cognitive behavioral therapy for social anxiety disorder. J Affect Disord2014; 162: 61-6.

24- Pullmann H, Allik J. The rosenberg self-esteem scale: its dimensionality, stability and personality correlates in Estonian. Pers Individ Dif2000; 28(4): 701-15.

25- Greenberger E, Chen C, Dmitrieva J, Farruggia SP. Item-wording and the dimensionality of the Rosenberg self-esteem scale: do they matter? Pers Individ Dif2003; 35(6): 1241-54.

26- Connor KM, Davidson JR, Churchill LE, Sherwood A, Foa E, Weisler RH. Psychometric properties of the Social Phobia Inventory (SPIN) New self-rating scale. $\mathrm{Br}$
J Psychiatry2000; 176(4): 379-86.

27- Christensen P, Prout A. Children, place, space and generation. In: Mayall B, Zeiher H, Org. Childhood in generational perspective (bedford way papers). London: Institute of Education; 2003.

28- Danger S, Landreth G. Child-centered group play therapy with children with speech difficulties. Int J Play Ther2005; 14 (1): 81-102.

29- Wethinton HR, Hahn RA, Fugua-Whiteley DS, et al. The effectiveness of nterventions to reduce psychology harm form traumatic events among child and adolescents. Am J Preventive Med2008; 53(3): 287-373.

30- Siahkalroudi SG, Bahri MZ. Effectiveness of cognitive behavioral play therapy group on self-esteem and social skills in girls' elementary school. Journal of Scientific Research and Development2015;2(4): 114-20.

Copyright(C) 2016 ASP Ins. This open-access article is published under the terms of the Creative Commons Attribution-NonCommercial 4.0 International License which permits Share (copy and redistribute the material in any medium or format) and Adapt (remix, transform, and build upon the material) under the Attribution-NonCommercial terms. 